\title{
Metode Hot Fit untuk Mengukur Tingkat Kesiapan SIM RS dalam Mendukung Implementasi E-Health
}

\author{
Titin Wahyuni ${ }^{1}$, Anif Parasetorini ${ }^{2}$ \\ ${ }^{1}$ Prodi Rekam medis dan Informasi Kesehatan, ${ }^{2}$ Prodi Administrasi Rumah Sakit \\ STIKES Yayasan RS Dr. Soetomo \\ email: titin@stikes-yrsds.ac.id
}

\begin{abstract}
E-Health is part of the Surabaya city e-governance and it is applied to two hospitals that are chosen as pilot projects, one of them is RSUD Dr. Soewandhie. E- Health aims to save outpatients'queuing time. This breakthrough through E-Health is expected to make it easier for patients to register from home through the website. However, the application need some supportby hospital's information systemwhich is easy to access by the registration officer and for filing officers about some information of patients. This study aims to identify SIM RS readiness in the application of e-health by using the HOT Fit model. The Hot Fit method has several variables, namely: human, organization, technology and net benefits. The population in this study were all registration officers and filling officers of RSUD $d r$. M. Soewandhi who was taken in total sampling. The variables studied are elements of the HOT Fit model. Data from the questionnaire were analyzed using descriptive statistics. The results of the study are that Organization is a factor that must be corrected immediately because it has a bad rating of $10 \%$, good enough $70 \%$ and very good at $20 \%$. Technological factors considere to be good at $85 \%$ and very good at $15 \%$. Human factors achieve abad rating at $5 \%$ while $30 \%$ are in a good rating, and $65 \%$ are in very good rating. Net benefitsstate to be in a beneficial condition to the point of being very useful, which ranges from 20-80\%. This can be said that the benefits of SIMRS are at good level perceived by the user.
\end{abstract}

Keywords: e-health, HOT Fit, outpatient, hospital, Information System

\begin{abstract}
ABSTRAK
E-Health merupakan bagian dari e-governance pemerintah kota Surabaya dan diterapkan kepada dua RS yang menjadi pilot project, salah satunya RSUD Soewandhie, yang bertujuan untuk menghemat waktu antrian pada instalasi rawat jalan melalui pemanfaatan teknologi informasi.Terobosan melalui E-Health ini diharapkan dapat memudahkan pasien untuk mendaftarkan diri dari rumah melalui website. Penerapan system ini memerlukan dukungan SIM RS yang mudah untuk diakses oleh petugas pendaftaran dan bagi petugas filing memudahkan untuk mencari rekam medis pasien melalui perintah pencarian dan histori pasien di SIM RS. Penelitian ini bertujuan untuk mengidentifikasi kesiapan SIM RS dalam penerapan aplikasi e-health denganmenggunakan model HOT Fit. Metode Hot Fit memiliki beberapa variable yaitu : human, organization, technology dan net benefit (manfaat).Populasi pada penelitian ini adalah semua petugas pendaftaran dan petugas fillingRSUD dr. M. Soewandhi yang diambil secara total sampling. Variabel yang diteliti adalah unsur-unsur dari model HOT Fit. Data hasil penyebaran kuisioner dianalisis menggunakan statistik deskriptif. Hasil penelitian adalah Organisasi merupakan faktor yang harus segera diperbaiki karena memiliki penilaian tidak baik sebesar $10 \%$, cukup baik $70 \%$ dan sangat baik sebesar $20 \%$. Faktor teknologi dinilai cukup baik sebesar $85 \%$ dan sangat baik sebesar $15 \%$.Faktor human menunjukkan dalam keadaan $5 \%$ berada dalam keadaan tidak baik sedangkan $30 \%$ berada dalam keadaan cukup baik dan $65 \%$ berada dalam keadaan sangat baik. Manfaat (net benefit) dapat dikatakan berada dalam keadaan cukup bermanfaat sampai dengan sangat bermanfaat, yaitu berkisar $20-80 \%$. Hal ini dapat dikatakan manfaat SIMRS berada pada level dirasakan oleh pengguna. Kesimpulan adalah Kekuatan faktor HOT-FIT SIMRS di Rumah Sakit Dr. Soewandhie ini terletak pada faktor manfaat dan teknologi dan kelemahannya adalah pada faktor organisasi
\end{abstract}

Kata kunci: e-health, HOT Fit, Rawat Jalan, Rumah Sakit, Sistem Informasi 


\section{PENDAHULUAN}

Berdasarkan Peraturan Walikota Surabaya No.5 tahun 2013 tentang pendoman pemanfaatan teknologi informasi dan komunikasi, Pemkot Surabaya mengembangkan beberapa teknologi informasi di bidang pemerintahan atau e-government. Salah satu inovasi e-government di bidang pelayanan kesehatan adalah $e$-health yang merupakan sebuah sistem informasi kesehatan terintegrasi yang dibangun dan dikembangkan oleh pemerintahan Kota Surabaya atas gagasan dari Dinas Kota Kesehatan Kota Surabaya (http://dinkes.surabaya.go.id).

Layanan e-health diterapkan pada 62 Puskesmas dan 2 RSUD milik Pemkot Surabaya yaitu RSUD dr. M. Soewandhi dan RSUD Bhakti Dharma Husada. Pelayanan e-health ditujukan terutama untuk pendaftaran online. Selain itu e-health juga digunakan untuk menjadi bagian manajemen logistik obat, data pengunjung, 10 pelayanan terbanyak di kedua rumah sakit tersebut (http://jpnn.com).

Pendaftaran online melalui pemanfaatan $e$-health bertujuan untuk menghemat waktu antrian pada inslasi rawat jalan. Dengan adanya pendaftaran online ini, pasien dapat mendaftarkan diri di rumah, melalui web yang dapat diakses dengan. Setelah selesai mendaftarkan diri, pasien akan mendapatkan nomor antrian yang dapat digunakan untuk registrasi ulang dibagian pendaftaran agar bisa langsung menunggu untuk mendapatkan pelayanan pengobatan.

Sistem pendaftaran manualdi fasilitas pelayanan kesehatan yang berlaku sebelum diberlakukan $e$-health yaitu pasien mengantri dalam pengambilan nomor lalu menunggu hingga nomor antriannya terpanggil dan menunggu lagi untuk mendapatkan pelayanan yang sesungguhnya. Banyak waktu yang digunakan untuk menunggu, sehingga dapat menyebabkan pasien jenuh. Akibat dari kondisi tersebut tidak sedikit pasien yang mengajukan komplain akan lamanya pelayanan yang diterima.

Keberhasilan e-health ini juga memerlukan faktor kesiapan rumah sakit, khususnya bagian pendaftaran pasien terkait dengan kesiapan rekam medis pasien. Berdasarkan observasi awal selama 5 hari, petugas pendaftaran akan menyiapkan rekam medis bagi pasien yang sudah melakukan pendaftaran melalui e-health pada malam hari sebelum pelayanan dilaksanakan. Masalah yang kami temukan selama observasi adalah tidak semua rekam medis ditemukan pada rak penyimpanan (misfile rekam medis), dan juga ditemukan rekam medis tanpa nama pasien. Tingkat kecepatan petugas dalam mencari rekam medis sangat dibantu oleh keberadaan SIM RS. Begitu juga petugas pendaftaran di loket juga memerlukan SIM RS yang mumpuni dalam menunjang aktifitasnya sehari-hari. Oleh karena itu penelitian bertujuan untuk mengevaluasi tingkat kesiapan SIM RS dengan menggunakan model HOT-FIT dalam mendukung implementasi e-health yang merupakan bagian dari e-governance di wilayah pemerintah kota Surabaya.

\section{METODE PENELITIAN}

Penelitian ini menggunakan Analisa data deskriptif dengan pengambilan data secara cross sectional. Populasi penelitian adalah seluruh petugas pendaftaran di loket dan petugas filing di bagian RM. Instrumen penelitian adalah kuesioner.

\section{HASIL DAN PEMBAHASAN}

Variabel HOT-FIT terdiri dari human yaitu system use dan satisfaction user; technology yang terdiri dari faktor system quality, information quality dan service quality; Organization yaitu structure organization dan environment organization dan manfaat. Saputra, Bayu Andika dan Muhimmah Izzati, 2013 dalam penelitiannya yang berjudul “ Evaluasi Faktor-Faktor Kesuksesan Implementasi Sistem Informasi Manajemen Rumah Sakit di PKU Muhamadiyah Sruweng dengan Menggunakan Metode HOT-FIT" menggunakan estimasi model PLS untuk menggambarkan pengaruh antar variable. Penelitian tersebut menyatakan semakin baik dan tepat ketiga faktor (human, teknologi dan organisasi) maka semakin tinggi manfaat yang didapatkan dari penerapan SIMRS. Variabel HOT-FIT terdiri dari human yaitu system use dan satisfaction user; technology yang terdiri dari faktor system quality, information quality dan service quality; Organization yaitu structure organization dan environment organization dan manfaat.

Faktor human menunjukkan dalam keadaan 5\% berada dalam keadaan tidak baik sedangkan 30\% berada dalam keadaan cukup baik dan $65 \%$ berada dalam keadaan sangat baik. Berdasarkan hal itu maka faktor human dapat dikatakan dalam keadaan baik. Faktor yang perlu diperbaiki dalam human adalah kepuasan pada pengguna, karena memiliki angka 
Titin Wahyuni dan Anif Parasetorini. Metode Hot Fit untuk Mengukur Tingkat Kesiapan SIM RS....

ketidakpuasan terhadap SIMRS sebesar 1\%. Hasil ini sejalan dengan mayoritas latar belakang pendidikan, usia responden yang berada dalam usia produktif dan dewasa muda.

Faktor teknologi secara bersama dengan manfaat (net benefit) merupakan faktor yang paling baik penilaiannya diantara faktor HOT-FIT yang lain yaitu dengan oranisasi dan human. Hal ini disebabkan technology tidak memiliki penilaian tidak baik, dan hanya memiliki penilaian cukup baik sebesar $85 \%$ dan sangat baik sebesar $15 \%$.

Organisasi merupakan faktor yang harus segera diperbaiki karena memiliki penilaian tidak baik sebesar 10\%, cukup baik $70 \%$ dan sangat baik sebesar $20 \%$. Terutama pada faktor struktur organisasi yaitu pada perlunya dilakukan penambahan pelatihan bagi pengguna SIMRS, kebijakan mengenai bantuan fasilitas penggunaan dan perbaikan jaringan sehingga mengurangi angka kejadian eror pada jam sibuk dan peningkatan kepuasan pengguna SIMRS.

Manfaat (net benefit) dapat dikatakan berada dalam keadaan cukup bermanfaat sampai dengan sangat bermanfaat, yaitu berkisar 20-80\%. Hal ini dapat dikatakan manfaat SIMRS berada pada level dirasakan oleh pengguna.

\section{Tabel Distribusi Kesiapan SIMRS dalam Mendukung Pelayanan E-Health Berdasarkan Model HOT-FIT}

\begin{tabular}{|c|c|c|c|c|c|c|c|c|}
\hline \multirow[b]{2}{*}{ Variabel } & \multirow[b]{2}{*}{$\begin{array}{c}\text { Sub } \\
\text { variabel }\end{array}$} & \multicolumn{6}{|c|}{ Pilihan Jawaban } & \multirow[b]{2}{*}{ Total } \\
\hline & & $\begin{array}{l}\text { Sering } \\
\text { digu- } \\
\text { nakan }\end{array}$ & $\begin{array}{c}\text { Cukup } \\
\text { sering } \\
\text { digu- } \\
\text { nakan }\end{array}$ & $\begin{array}{c}\text { Jarang } \\
\text { digu- } \\
\text { nakan }\end{array}$ & $\begin{array}{l}\text { Tidak } \\
\text { puas }\end{array}$ & $\begin{array}{l}\text { Cukup } \\
\text { puas }\end{array}$ & Puas & \\
\hline \multirow[b]{2}{*}{ Human } & $\begin{array}{l}\text { system } \\
\text { use }\end{array}$ & $\begin{array}{c}8 \\
(40 \%)\end{array}$ & $\begin{array}{c}12 \\
(60 \%)\end{array}$ & 0 & & & & $\begin{array}{c}20 \\
(100 \%)\end{array}$ \\
\hline & $\begin{array}{l}\text { user } \\
\text { satis- } \\
\text { faction }\end{array}$ & & & & $(5 \%)$ & $\begin{array}{c}5 \\
(25 \%)\end{array}$ & $\begin{array}{c}14 \\
(70 \%)\end{array}$ & $\begin{array}{c}20 \\
(100 \%)\end{array}$ \\
\hline \multirow{3}{*}{$\begin{array}{l}\text { Tech- } \\
\text { nology }\end{array}$} & $\begin{array}{l}\text { sistem } \\
\text { quality }\end{array}$ & & & & 0 & $\begin{array}{c}20 \\
(100 \%)\end{array}$ & 0 & $\begin{array}{c}20 \\
(100 \%)\end{array}$ \\
\hline & $\begin{array}{l}\text { infor- } \\
\text { mation } \\
\text { quality }\end{array}$ & & & & $\begin{array}{c}1 \\
(5 \%)\end{array}$ & $\begin{array}{c}7 \\
(35 \%)\end{array}$ & $\begin{array}{c}12 \\
(60 \%)\end{array}$ & $\begin{array}{c}20 \\
(100 \%)\end{array}$ \\
\hline & $\begin{array}{l}\text { service } \\
\text { quality }\end{array}$ & & & & $\begin{array}{c}3 \\
(15 \%) \\
\end{array}$ & $\begin{array}{c}10 \\
(50 \%) \\
\end{array}$ & $\begin{array}{c}7 \\
(35 \%) \\
\end{array}$ & $\begin{array}{c}20 \\
(100 \%) \\
\end{array}$ \\
\hline \multirow{2}{*}{$\begin{array}{l}\text { Organi- } \\
\text { zation }\end{array}$} & $\begin{array}{l}\text { struc- } \\
\text { ture } \\
\text { organi- } \\
\text { zation }\end{array}$ & & & & $\begin{array}{c}1 \\
(5 \%)\end{array}$ & $\begin{array}{c}15 \\
(75 \%)\end{array}$ & $\begin{array}{c}4 \\
(20 \%)\end{array}$ & $\begin{array}{c}20 \\
(100 \%)\end{array}$ \\
\hline & $\begin{array}{l}\text { envi- } \\
\text { ron- } \\
\text { ment }\end{array}$ & & & & $\begin{array}{c}2 \\
(10 \%)\end{array}$ & $\begin{array}{c}6 \\
(30 \%)\end{array}$ & $\begin{array}{c}12 \\
(60 \%)\end{array}$ & $\begin{array}{c}20 \\
(100 \%)\end{array}$ \\
\hline Manfaat & & & & & 0 & $\begin{array}{c}16 \\
(80 \%)\end{array}$ & $\begin{array}{c}4 \\
(20 \%)\end{array}$ & $\begin{array}{c}20 \\
(100 \%)\end{array}$ \\
\hline
\end{tabular}

Tabel Kategori Penilaian HOT pada Kategori Human, Technology dan Organization

\begin{tabular}{|c|c|c|c|c|}
\hline \multirow[b]{2}{*}{ Variabel HOT } & \multicolumn{3}{|c|}{ Penilaian } & \multirow[b]{2}{*}{ Total } \\
\hline & $\begin{array}{l}\text { Tidak } \\
\text { baik }\end{array}$ & $\begin{array}{l}\text { Cukup } \\
\text { Baik }\end{array}$ & $\begin{array}{c}\text { Sangat } \\
\text { Baik }\end{array}$ & \\
\hline Human & $1(5 \%)$ & $6(30 \%)$ & $\begin{array}{c}13 \\
(65 \%)\end{array}$ & $\begin{array}{c}20 \\
(100 \%)\end{array}$ \\
\hline Technology & 0 & $\begin{array}{c}17 \\
(85 \%)\end{array}$ & $\begin{array}{c}3 \\
(15 \%)\end{array}$ & $\begin{array}{c}20 \\
(100 \%)\end{array}$ \\
\hline Organization & $\begin{array}{c}2 \\
(10 \%) \\
\end{array}$ & $\begin{array}{c}14 \\
(70 \%)\end{array}$ & $\begin{array}{c}4 \\
(20 \%) \\
\end{array}$ & $\begin{array}{c}20 \\
(100 \%)\end{array}$ \\
\hline
\end{tabular}

Tabel Kategori Penilaian HOT pada Manfaat

\begin{tabular}{ccccc}
\hline \multirow{2}{*}{$\begin{array}{c}\text { Variabel } \\
\text { HOT }\end{array}$} & $\begin{array}{c}\text { Tidak ber- } \\
\text { manfaat }\end{array}$ & $\begin{array}{c}\text { Cukup } \\
\text { ber- } \\
\text { manfaat }\end{array}$ & $\begin{array}{c}\text { Sangat } \\
\text { ber- } \\
\text { manfaat }\end{array}$ & Total \\
\hline Manfaat & 0 & $16(80 \%)$ & $4(20 \%)$ & $\begin{array}{c}20 \\
(100 \%)\end{array}$ \\
\hline
\end{tabular}

Hasil dari sisi human pada penelitian ini menunjukkan $5 \%$ berada dalam keadaan tidak baik sedangkan 30\% berada dalam keadaan cukup baik dan $65 \%$ berada dalam keadaan sangat baik.

Kepuasan pengguna yang berada pada kategori baik pada penelitian ini dan frekuensi pemanfaatan SIMRS yang cukup tinggi menunjukkan bahwa system ini tidak menujukkan adanya masalah dari sisi variable human. Dan juga ditunjang dari sisi pengguna yang berada pada usia muda, dengan tingkat pendidikan yang cukup tinggi dan pengalaman kerja yang berada pada level motivasi dan produktivitas tinggi.

Faktor yang perlu diperbaiki dalam human adalah kepuasan pada pengguna, karena memiliki angka ketidakpuasan terhadap SIMRS sebesar 1\%. Hasil ini sejalan dengan mayoritas latar belakang pendidikan, usia responden yang berada dalam usia produktif dan dewasa muda. Perlu dilakukan peningkatan pelatihan dan perlu dijelaskan secara terinci dan jelas mengenai pengguna sistem informasi dalam job deskripsi, dan Standart Operasional Prosedur (SOP).

Penelitian Pratiwi, Sudjaswadi and Kusnanto, 2012; Diantono and Winarno, 2018 bahwa variabel human dan technology bersama-sama memberikan pengaruh terhadap net benefit. Hasil Diantono and Winarno, 2018 menyatakan semakin tinggi kepuasan 
pengguna maka semakin baik net benefit yang diterima. Kepuasan pengguna juga mempengaruhi penggunaan system, hal ini dinyatakan dari hasi penelitian Saputra, Andika Bayu, 2016.

Hasil berbeda didapatkan pada penelitian yang dilakukan oleh Murnita, R., Sediyono, E. and Purnami, C.T., 2016 dimana menyatakan bahwa faktor human yang disebabkan oleh belum adanya pelatihan dan kepatuhan petugas yang kurang baik pada SPO yang menyebabkan keterlambatan pembetulan jika terjadi kesalahan pada system. Lebih lanjut hasil penelitian ini menyatakan bahwa faktor human berkaitan erat dengan organisasi. Senada dengan hasil penelitian Prasetyowati, A. and Kushartanti, R., 2018, meskipun faktor human sudah baik, pelatihan tetap perlu untuk ditingkatkan. Dalam mengadopsi suatu teknologi informasi di rumah sakit, maka perlu untuk mempertimbangkan kapabilitas dari sumber daya manusia (Lian, Yen and Wang, 2016). Organisasi merupakan faktor yang harus segera diperbaiki karena memiliki penilaian tidak baik sebesar $10 \%$ dan terutama pada faktor struktur organisasi yaitu pada perlunya dilakukan penambahan pelatihan bagi pengguna SIMRS, kebijakan mengenai bantuan fasilitas penggunaan dan perbaikan jaringan sehingga mengurangi angka ketidakpuasan pengguna.

Aspek human berkaitan dengan organisasi, misalnya dari kebijakan pelatihan terutama bagi pegawai baru atau pegawai yang belum pernah mendapatkan pelatihan. Meskipun pelatihan ini ada namun apabila pengguna ternyata merasa bahwa ketrampilannya tidak berasal dari hasil pelatihan namun dari bantuan dari rekan kerja maka bisa dikatakan, pelatihan yang telah dijalani juga tidak bermanfaat (Saputra, Bayu Andika dan Muhimmah Izzati, 2013; Murnita, R., Sediyono, E. and Purnami, 2016).

SIMRS perlu dilakukan monitoring dan evaluasi untuk menunjukkan bahwa organisasi memberikan dukungan nyata pada pengorasian SIMRS. Peran organisasi sangat penting terutama saat pengenalan system sehingga dapat meningkatkan penerimaan penggunaan dan partisipasi dari system use(Murnita, R., Sediyono, E. and Purnami, 2016). Sedangkan pada penelitian Pratiwi, Sudjaswadi and Kusnanto, 2016 human dan organisasi bersama-sama mempengaruhi net benefit.

Faktor technologi secara bersama dengan manfaat (net benefit) merupakan faktor yang paling baik penilaiannya diantara faktor HOT-FIT yang lain yaitu dengan oranisasi dan human. Hal ini disebabkan technology tidak memiliki penilaian tidak baik, dan hanya memiliki penilaian cukup baik. Variabel human, organisasi dan teknologi bersama-sama mempengaruhi net benefit (Diantono and Winarno, 2018; Pratiwi, Sudjaswadi and Kusnanto, 2016) dan keberhasilan teknologi memberikan pengaruh kepada kepuasan pengguna (Prasetyowati, A. and Kushartanti, 2018). Hasil yang berbeda didapatkan pada penelitian Murnita, R., Sediyono, E. and Purnami, 2016, meskipun variabel human dan organisasi memberikan penilaian kurang baik, namun sepanjang system bekerja dengan baik, maka tetap memberikan kepuasan kepada pengguna.

\section{SIMPULAN}

Variabel HOT yang paling baik adalah human (system use) dan teknologi (system quality) dan manfaat. Varibel HOT yang perlu diperbaiki adalah organisasi.Kekuatan faktor HOT-FIT SIMRS di Rumah Sakit Dr. Soewandhie ini terletak pada faktor manfaat dan teknologi dan kelemahannya adalah pada faktor organisasi

Penelitian ini merekomendasikan Rumah Sakit Dr. Soewandhie untuk meningkatkan faktor yang berhubungan dengan peningkatan faktor human yaitu peningkatan pelatihan, kebijakan mengenai bantuan fasilitas mengenai bantuan fasilitas penggunaan dan perbaikan jaringan sehingga mengurangi angka kejadian eror pada jam sibuk dan peningkatan kepuasan pengguna SIMRS. Disamping itu RSUD Dr. Soewandhie harus meningkatkan sub variabel service quality yaitu komunikasi antara bagian IT dengan pengguna dan segi kebijakan pihak manajemen rumah sakit dalam mendukung implemntasi SIMRS.

\section{DAFTAR PUSTAKA}

Bayu,Andika \& Muhimmah, Izzati. 2013. Evaluasi Faktor-Faktor Kesuksesan Implementasi Sistem Informasi Manajemen Rumah Sakit di PKU Sruweng dengan Menggunakan Metode HOT fit. Seminar Nasional Informatika Medis (SNIMed) IV, p.78.2013. 9 November 2013, Magister Teknik Informatika, Fakultas Teknologi Industri, Universitas Islam Indonesia. 
Titin Wahyuni dan Anif Parasetorini. Metode Hot Fit untuk Mengukur Tingkat Kesiapan SIM RS....

DeLone, W.H. dan E. R. McLean. 2003. TheDeLone and McLean Modelof Information System Success: A ten-Year Update. Journal of Management Information Systems, 19 (4), 9-30. Diakses tanggal 16 Maret2017

Diantono, P. and Winarno, W. W. (2018) 'Evaluasi Penerapan SIMRS Menggunakan Metode HOT-Fit Di RSUD Dr. Soedirman Kebumen', Jurnal Ilmiah Penelitian dan Penerapan Teknologi Sistem Informasi, 2(1), pp. 46-56.

Eritamala, Shofana. 2013. Pendekatan hot-Fit Framework dalam Generalized Structural Component Analysis pada Sistem Informasi Manajemen Barang Milik Daerah: Sebuah Pengujian Efek Resiprokal. Jurnal Akuntansi dan Investasi, Vol.17 No.2, Hlm:141-157, Juli 2016.

Krisbiantoro, Dwi., Suyanto, M., \& Luthfi, Emha Taufiq. 2015. Evaluasi Keberhasilan

Implementasi Sistem Informasi Dengan pendekatan HOT FIT Model. Konferensi Nasional Sistem dan Informatika 2015. STMIKSTIKOM Bali, 9-10 Oktober 2015.

Lian, J. W., Yen, D. C. and Wang, Y. T. (2016) 'An exploratory study to understand the critical factors affecting the decision to adopt cloud computing in Taiwan hospital', International Journal of Information Management. Elsevier Ltd, 34 (1), pp. 28-36. doi: 10.1016/j. ijinfomgt. 2013. 09.004.

Ma, WaiWing Ada. 2016. Usability Testof E-Health Promotion@HKIEd-a

Community of Practice Platformto Promote Healthty Lifestyles. Healh, 2016, 8, 615-622. Publised on May 2016 in SciRes.http:www.scrip.org// journal/health

Mediakom Kemenkes RI. 2015. E-Health, Layanan Kesehatan Ramah Masyarakat di Jawa Timur. http://mediakom.sehatnegeriku.com/e-healthlayanan-kesehatan-ramah-masyarakat-dijawa-timur/. Diakses tanggal 24 Maret2017
Murnita, R., Sediyono, E. and Purnami, C. T. (2016) 'Evaluasi Kinerja Sistem Informasi Manajemen Farmasi di RS Roemani Muhammadiyah Dengan Metode HOT Fit', Jurnal Manajemen Kesehatan Indonesia, 04(01), pp. 11-19.

Muhimmah, I., 2013. Evaluasi Faktor-Faktor Kesuksesan Implementasi Sistem Informasi manajemen Rumah Sakit di PKU Muhammadiyah Sruweng dengan Menggunakan Metode Hot-Fit. In Seminar Nasional Informatika Medis (SNIMed).

Nielson,Jacob,Usability 101:Introductiontousability. http://www.useit.com/alertbox/20030825. html. Diakses tanggal 24 Maret2017

Prasetyowati, A. and Kushartanti, R. (2018) 'Pengaruh Faktor HOT (Human, Organisasi, Dan Teknologi) Terhadap Kepuasan Pengguna Sistem Informasi Primary Care Di Wilayah Kota Semarang', Jurnal Manajemen Informasi Kesehatan Indonesia, 6 (1), pp. 63-67.

Pratiwi, A., Sudjaswadi, R. and Kusnanto, H. (2016) 'Analisis Penerapan Sistem Informasi Manajemen Farmasi Di Rumah Sakit Mata Dr.Yap Yogyakarta Dengan HOT-FIT Model', Jurnal Manajemen dan Pelayanan Farmasi, 2 (1), pp. 45-49.

Saputra, A.B., 2016. Identifikasi Faktor-Faktor Keberhasilan Implementasi Sistem Informasi Manajemen Rumah Sakit. Jurnal Penelitian Pers dan Komunikasi Pembangunan, 19(3).

Yusof, M.M., Kuljis, J., Papazafeiropoulou, A. and Stergioulas, L.K., 2008. An evaluation framework for Health Information Systems: human, organization and technology-fit factors (HOT-fit). International Journal of Medical Informatics, 77 (6), pp.386-398.

Zulkifli, Nurul Ilmi \& Sutomo, AdiHeru. 2016. Usability Testing Sistem Informasi Pendonor Darah (Studi kasus di Unit Pelayanan Transfusi Darah RSUP Dr. Sardjito Yogyakarta. Journal of System Information for Public Health, Vol1, No.1, April 2016. Hal 10-15. 